\title{
Bioassay Guided Phytometabolites Extraction for Screening of Potent Antimicrobials in Passiflora foeti da L.
}

\author{
Patil A.S.* and Paikrao H.M \\ Department of Biotechnology, Sant Gadge Baba, Amravati University, Amravati (MS), 444602 India.
}

\section{ARTICLE INFO}

Article history:

Received on: 11/08/2012

Revised on: 29/08/2012

Accepted on: 08/09/2012

Available online: 28/09/2012

Kay words: Passiflora foetida L., Phytochemicals, TLC-

bioautography, antimicrobial activity, polyacetylenes

\begin{abstract}
Passiflora is a genus belonging to the family Passifloraceae having varied species with highly therapeutic values. Tribes with traditional medicinal knowledge suggested Passiflora foetida $\mathrm{L}$. as a source of high value pharmaceutical plant. Present study deals with the Isolation, Purification, characterization and bioassays of antimicrobial secondary metabolites. In spite of traditional soxhlet extraction, Cold percolation proved suitable extraction scheme. Bioassay guided TLC characterization, and purification led the effective collection of bioactive natural products. Disc diffusion method shows a potent inhibitory activity of compounds against multi drug resistant pathogenic microorganisms like $S$. aureus $(O A R S)$. For structural characterization bioactive products were analyzed using UV. The results confirmed the presence of polyacetylenes as active constituents in the plant.
\end{abstract}

\section{INTRODUCTION}

The genus Passiflora belongs to Passifloraceae family and includes the passion fruit, is the largest and the most widespread genus of tropical flora. About 400 species of this genus are grouped into 21 subgenera (Cronquist, 1981). More than 350 species have been found in tropical regions and rain forests of South America (Killip, 1938) and 60 of them are edible species. Passion fruit is an important fruit crop in many exotic and subtropical countries due to its edible fruits, ornamental use and medicinal properties. Some species (P. edulis, P. quadrangularis and $P$. ligularis). are chiefly cultivated for the production of fruit juice. $P$. incarnata is reputed for its sedative properties, and several other species are known for their ethnobotanical uses.

* Corresponding Author

Email: anitapatil@sgbau.ac.in, Faxno.91-0721-2662135; 2660949

Telephone (O) 91-721-2662208 ext 267,091- 9881735354 (Mobile)
P. amethystina Mikan, found in the rain forest of the Brazilian south-eastern coast (Fouqué, 1972), is a wild passion fruit species. It has purple-blue flowers, which are very aromatic. The genus also contains some species of ornamental use and medicinal properties as sedatives, antispasmodics and antibacterial (Nhut et al., 2007). Several species have edible fruits and attractive flowers, about 40 species have been cultivated, but fewer than 6 are fruit crops in the neotropics and only one, $P$. edulis (and its varieties, such as the yellow favicarpa), is economically important. A few species, such as $P$. foetida and $P$. lonchocarpa, are extremely foul smelling (Benson et al., 1976). Eleven species, including $P$. foetida and $P$. tripartita $(=P$. mollissima $)$ are recorded as weeds in distinctive parts of the world (Swarbrick 1981). Both P. foetida and $P$. tripartita are closely related taxonomically, whereas, $P$. edulis belongs to a different subgenus (Waage et al., 1981) and is the only economic crop at risk from oligophagous insects attacking 
$P$. foetida. In recent years, a significant revival of interest in natural products as a potential source for new medicines has been observed throughout the world. Several modern drugs $\sim 40 \%$ in use have been developed from natural products. Nowadays, multiple drug resistance in human pathogenic microorganisms develops due to indiscriminate use of commercial chemical antimicrobial drugs commonly used in the treatment of human diseases. Over the last three centuries, intense efforts have been made to discover clinically useful antimicrobial drugs (Ahmed et al., 1998; Sarker et al., 2006; Werner et al., 1999). The increasing interest on traditional ethno medicine may lead to discovery of novel therapeutic agents. The World Health Organization (2000) estimates that $80 \%$ of the population of developing countries still relies on traditional medicines, mostly plant drugs, for their primary health care needs. Herbs are supposed to be safe, but many unsafe and fatal side effects have recently been reported (Ikegami et al., 2003; Izzo, 2004).

Traditionally, fresh or dried whole plants as well as their preparations are accepted for medicinal use in America, Germany, France, and other European countries for the treatment of nervous anxiety (Blumenthal, 1997; Speroni and Minghetti, 1988). Pharmacological studies show that passion flower has antispasmodic, sedative, anxiolytic, and hypotensive activity (Akhondzadeh et al., 2001; Abascal and Yarnell, 2004; Dhawan et al., 2001a; 2001b; Dhawan et al., 2003; Weiss, 1988; Wolfman et al., 1994).

A passion flower (Passiflora foetida), an exotic and fastgrowing perennial vine, is found in the Western USA and in Asian countries like India. Ethnobotanical reviews of $P$. foetida report the decoction of leaves and fruits to treat asthma and biliousness (Ambasta, 1986); and leaf paste is applied on the head for giddiness and headache (Chopra et al., 1956). In Brazil, the herb is used in the form of lotions or poultices to treat erysipelas and skin diseases with inflammation (Chopra et al., 1944). The major phytoconstituents of this plant are alkaloids, phenols, glycoside flavonoids, and cyanogenic compounds, passifloricins, polyketides, and alpha-pyrones (Dhawan et al., 2004; Echeverri et al., 2001). One chemical component of a passion flowers Passicol, a polyacetylenic compound has antimicrobial activity (Birner and Nicolls, 1973; Nicolls, 1970; Nicolls et al., 1973), which is still not reported in $P$. foetida $\mathrm{L}$. The majority of the active components in this plant are C-glycosyl flavones based on apigenin and luteolin; Harman alkaloids are found in trace amounts along with sucrose and trace amounts of volatile oil (Bradley, 1992; Leung and Froster, 1996; Newall et al., 1996).

\section{MATERIALS AND METHODS}

Leaves and fruits of $P$. foetida L. was collected from the Melghat forest area, Amravati, India. The plant was authenticated using standard flora and cross-checked with herbarium records at the NBRI, Lucknow, India as Passiflora foetida L. with an accession number- 98181. Silica gel-GF 254 was purchased from Himedia Laboratories, India and all other reagents and solvents were purchased from Sigma-Aldrich, St. Louis, MO, USA. The UV spectrophotometer-1800 (Shimadzu, Japan), and UV Transilluminator (Cleaver, Korea) was used for study and analysis.

\section{PRELIMINARY PHYTOCHEMICAL SCREENING}

The extracts of Passiflora foetida were analyzed for the presence of Alkaloids, Saponins, Tannins, Cardiac Glycoside, Anthraquinones, Steroid, coumarin, carbohydrates and flavonoids, according to standard methods (Odebiyi and sofowora, 1978; Sofowora, 1982; Williamson et. al., 1996; Banso and Ngbede, 2006; Ngbede et. al., 2008). For the study of phytochemical analysis, the ethanol extract of the plant leaves was prepared according to standard methods (Sofowora, 1982). The plant leaves were air dried and powdered. Transferred the powdered material into solvent extractor and extracted it with $95 \%$ ethanol for $72 \mathrm{~h}$. The extract was obtained as a brown gummy solid. The extract was stored and used for phytochemical screening.

\section{Screening for alkaloids}

Three grams of extract was stirred with ethanol containing 3\% tartaric acid. The filtrate was shared into 3 beakers and tested for alkaloids as follows-

In to the first beaker, Hagar's reagent was added into the second beaker, Mayer's reagent was added and into the last beaker Marquins reagent was added. Precipitations in any of 3 tests indicate the presence of an alkaloid (Odebiyi and sofowora, 1978; Banso and Ngbede, 2006)

\section{Screening for saponins}

About $0.5 \mathrm{~g}$ of the plant extract was shaken with water in a test tube, frothing, which persists on warming was taken as preliminary evidence for the presence of saponins.

Few drops of olive oil were added to $0.5 \mathrm{~g}$ of extract and vigorously shaken; formation of soluble emulsion in the extract indicates the presence of saponins (Odebiyi and sofowora, 1978).

\section{Screening for tannins}

Into $10 \mathrm{ml}$ of freshly prepared $10 \%$ potassium hydroxide $(\mathrm{KOH})$ in a beaker, $0.5 \mathrm{~g}$ of extract was added and shaken to dissolve. A dirty precipitate observed indicated the presence of tannin (Odebiyi and sofowora, 1978; Willimson et al., 1996).

\section{Screening for steroid}

Total 100mg of Passiflora foetida extract was dissolved in $2 \mathrm{ml}$ of chloroform. Sulphuric acid was carefully added to form a lower layer. A reddish-brown color at the interface is indicative of the presence of steroidal ring (Sofowora, 1982)

\section{Screening for flavonoids}

About $2 \mathrm{~g}$ of the powdered leaves was completely detanned with acetone. The residue was extracted in warm water after evaporating from the acetone in water bath. The mixture was filtered while still hot. The filtrate was cooled and used. 


\section{Sodium hydroxide test}

Five $\mathrm{ml}$ of $20 \%$ sodium hydroxide was added to equal volume of the detanned water extract. A yellow solution indicates the presence of flavonoid.

\section{Screening for anthraquinones}

Bontrager's test- About $0.5 \mathrm{~g}$ of the extract was taken in order to dry test tube and $5 \mathrm{ml}$ chloroform was added and shaken for $5 \mathrm{~min}$. The extract was filtered, and the filtrate shaken with an equal volume of $100 \%$ ammonia solution. A pink violet or red colour in the ammoniacal layer (lower layer) indicates the presence of free anthraquinones.

\section{Screening for cardiac glycoside}

(Keller Killiani test)- Total $100 \mathrm{mg}$ of extract was dissolved in $1 \mathrm{ml}$ of glacial acetic acid containing one drop of ferric chloride solution. This was then underlayerd with $1 \mathrm{ml}$ of concentrated sulphuric acid. A brown ring obtained at the interface indicates the presence of de-oxysugar characteristics of cardenolides.

\section{PREPARATION OF TANNIN FREE BIOACTIVE EXTRACT}

The schematic representation of procedure was given below as proposed by Wall et al., (1996).

$50 \mathrm{gm}$ dried leaf powder suspended in methanol and rotated on an orbital shaker for 4 days.

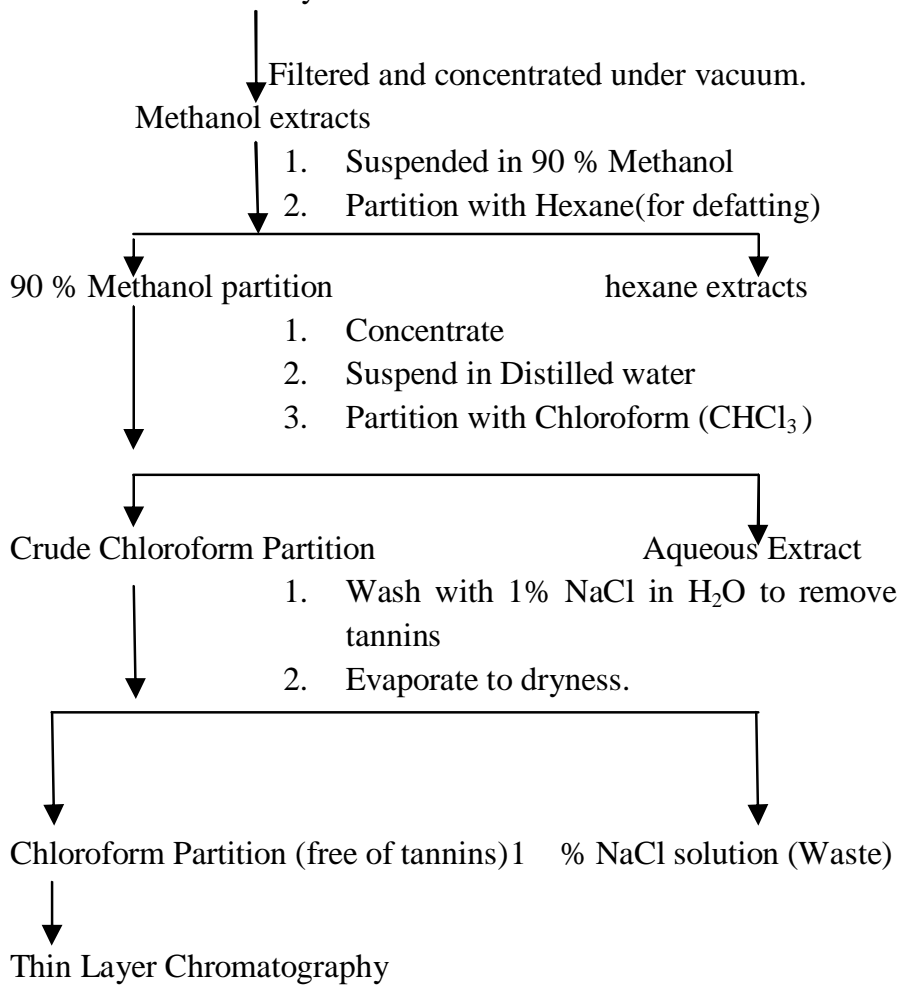

\section{TLC Characterization}

The presence of active metabolites in $P$. foetida $\mathrm{L}$. extract was evaluated by TLC plates. The preparative normal phase TLC was performed on $15 \times 10 \mathrm{~cm}$ glass plates coated with 1 $\mathrm{mm}$ layer of silica gel, dried in room temp. for 30 minutes and activated in the oven at $110^{\circ} \mathrm{C}$ for next 30 minutes. The solvent system chloroform: ethyl acetate: formic acid: methanol (5:3:2:0.4) 4 were used (Harborne, 1973). $10 \mu 1$ of extract was spotted on the silica plates. The experimental plates were developed in a chromatographic chamber, saturated by $100 \mathrm{ml}$ of the solvent system. Plate development required about 15 to 20 minutes; it was then visualized at $365 \mathrm{~nm}$ under UV transilluminator (Cleaver). Rf values of bands were recorded.

\section{TLC Bioautography}

In order to find out the bioactive fraction from TLC plate the TLC Bio-autography by agar overlay method was performed (Hostettmann et al, 1990). In N.A medium, a suspension of test pathogen Oxacilin resistant $S$. aureus (OARS) i.e. $10 \mathrm{mg} / 10 \mathrm{~mm}$ zone was added aseptically in the molten agar, further spread on the TLC plate. The plate kept in moist chambers and incubated at $37^{0} \mathrm{C}$ for overnight. Next the solution of tetrazolium salt MTT (3(4, 5-Dimethylthiazol-2-yl)-2, 5-Diphenyltetrazolium Bromide, $2 \mathrm{mg} / \mathrm{ml}$ ) was sprayed on the plate.

\section{Spectroscopic Analysis}

The bioactive fractions were scrapped from the TLC plate and Centrifuged in methanol, and the Purified fractions were UV analyzed in the range of $200-400 \mathrm{~nm}$ while the baseline was corrected keeping methanol as blank.

\section{Determination Of Minimum Inhibitory Concentration}

The antibacterial potency of the bioactive fraction in variable concentrations was determined in terms of minimum inhibitory concentration (MIC) using the filter paper disc diffusion method (Pelczar et al., 1998; Patil, 2010). The lawn of the log phase of Staphylococcus aureus, Salmonella typhi, Klebsiella pneumoniae, and Pseudomonas aeruginosa were prepared using a glass spreader. The variable concentrations of bioactive fraction were prepared in $1 \%$ DMSO (dimethyl sulphoxide) so that a single disc contained $0.5,1,2,3,4$ and $5 \mu \mathrm{g} / \mathrm{ml}$. The filter paper discs $(3 \mathrm{~mm})$ were presoaked in their respective dilutions for 30 min and then kept in the test bacterial lawn. The plates were left on a bench for $1 \mathrm{hr}$ before incubation at $37^{\circ} \mathrm{C}$ for $24 \mathrm{~h}$ to allow prediffusion of the extract (Esimone et al., 1998), control was maintained by soaking paper disc in $1 \%$ DMSO. The zone of inhibition was measured in $\mathrm{mm}$ using the zone measuring scale and compared with the control set (i.e. disc with solvent). The MIC value was taken as the lowest concentration of the extract showing complete lack of growth after the incubation period (EUCAST, 2000) or maximum inhibition of test microorganisms each experiment was performed in triplicates. 


\section{Statistical Analysis}

Data acquired was statistically analyzed using Microsoft Excel 2007.

\section{RESULTS AND DISCUSSION}

\section{Phytochemical Analysis}

The preliminary phytochemical analysis of $P$. foetida resulted in presence of all the principal classes of compounds discriminated in Table.1.

Table. 1: Preliminary phytochemical screening of ethanol extract of Passiflora foetida L.

\begin{tabular}{ll}
\hline Phytochemical constituents & Results \\
\hline Saponins & + \\
Tannins & + \\
Cardiac Glycosides & + \\
Alkaloid & + \\
Anthraquinones & + \\
Steroid & + \\
Flavonoid & + \\
Key + = present &
\end{tabular}

\section{Extraction Of Material}

The initial weight of leaf powder before extraction was $50 \mathrm{gm}$, after extraction the pure crude extracts was of $1.11 \mathrm{gm}$. The extraction scheme resulted in efficient method as it removed the tannins, Saponins and other interfering compounds.

\section{Spectroscopic Analysis}

The UV analysis of bioactive fractions showed multiple absorption maxima in the range of $230-370 \mathrm{~nm}$, confirming their polyacetylenic nature (Birner and Nicolls, 1973; Sorensen, 1968; Bohlman et al., 1961). The finger like appearance of spectrum (PA1) confirmed the presence of polyacetylenes (Fig.1).

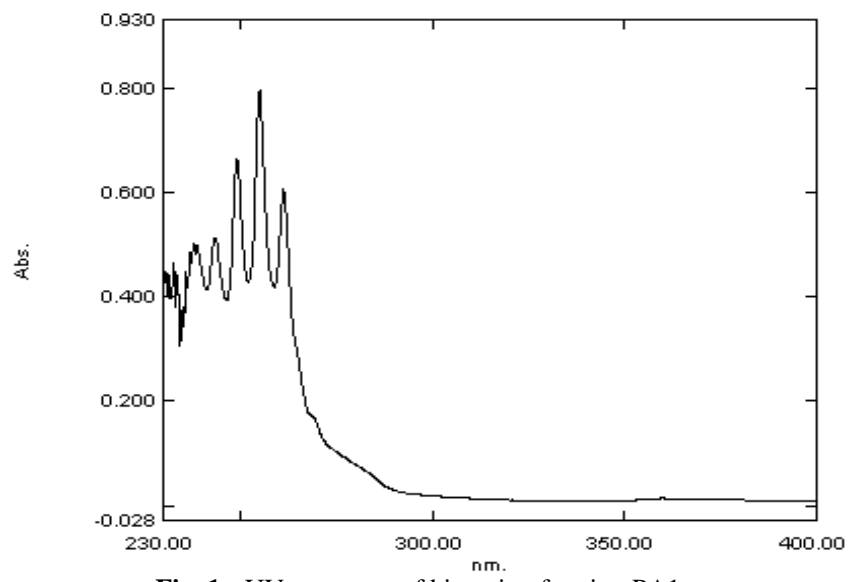

Fig. 1: UV spectrum of bioactive fraction PA1.

\section{Confirmative Test for Unsaturation}

To confirm the polyacetylenic nature of fraction, a bromine water test was performed, in which a bioactive spot from TLC plate was scrapped off and eluted with $2 \mathrm{ml}$ distilled water; plain distilled water with an equal amount of scrapped silica was kept as the control.. To $1 \mathrm{ml}$ of the test sample along with the control, $1 \mathrm{ml}$ of bromine water was added drop wise, and the color change was observed; the disappearance of bromine water color indicated unsaturation confirming the presence of polyacetylenes in fractions (Jamode et al., 1998).

\section{TLC Analysis}

The TLC analysis of extract resulted in showing two prominent green coloured band named as PA1 and PA2, i.e. Polyacetylene 1 and Polyacetylene 2 with Rf value 0.32 and 0.70 respectively (Fig. 2).

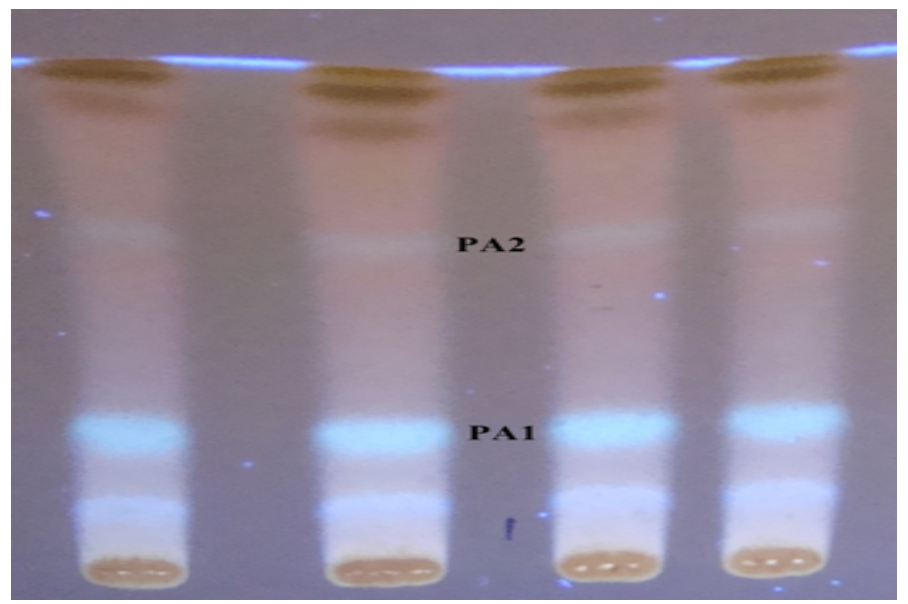

Fig. 2: TLC characterizations of bioactive fractions.

\section{TLC Bioautography}

The Bioautography of TLC plate revealed the presence of bioactive fractions as PA1 and PA2 both appeared as a white band against the violet background proving potent antimicrobial against multiple drug resistant $S$. aureus (Fig. 3).

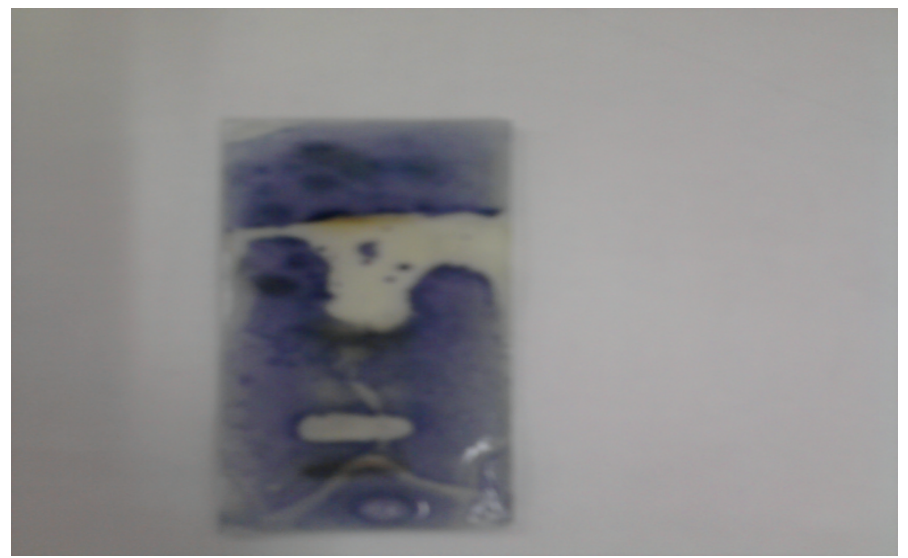

Fig. 3: TLC Bioautography by agar overlay assay of bioactive fractions PA1 and PA2.

\section{Disc Diffusion Assay}

Strains of Staphylococcus aureus, Salmonella typhi, Klebsiella pneumoniae, and Pseudomonas aeruginosa were selected to study the inhibitory effect of Fractions extracted from $P$. foetida L. The antibacterial activity was analyzed by disc diffusion techniques of both fractions eluted from the PA1 and 
Table. 2: Inhibitory effect of pure PA1 and PA2 fractions from P. foetida L. extracts.

\begin{tabular}{|c|c|c|c|c|c|c|c|c|c|}
\hline \multirow{3}{*}{ S.No } & \multirow{3}{*}{$\begin{array}{c}\text { Conc. of Passicol } \\
\mu \mathrm{g} / \mathrm{ml}\end{array}$} & \multicolumn{8}{|c|}{ Zone of Inhibition (mm) } \\
\hline & & \multicolumn{2}{|c|}{ S. aureus } & \multicolumn{2}{|c|}{ S. typhi } & \multicolumn{2}{|c|}{ K. pneumoniae } & \multicolumn{2}{|c|}{ P. aeruginosa } \\
\hline & & PA1 & PA2 & PA1 & PA2 & PA1 & PA2 & PA1 & PA2 \\
\hline 1 & Control & 3 & 3 & 3 & 3 & 3 & 3 & --- & ---- \\
\hline 2 & 0.5 & $12 \pm 0.16$ & $12 \pm 0.16$ & $13 \pm 0.16$ & $12 \pm 0.16$ & $12 \pm 0.16$ & $11 \pm 0.24$ & --- & --- \\
\hline 3 & 1 & $12 \pm 0.16$ & $12 \pm 0.16$ & $11 \pm 0.24$ & $12 \pm 0.16$ & $12 \pm 0.16$ & $12 \pm 0.16$ & --- & --- \\
\hline 4 & 2 & $12 \pm 0.16$ & $12 \pm 0.16$ & $12 \pm 0.16$ & $12 \pm 0.16$ & $12 \pm 0.16$ & $12 \pm 0.16$ & --- & --- \\
\hline 5 & 3 & $14 \pm 0.08$ & $13 \pm 0.16$ & $12 \pm 0.16$ & $13 \pm 0.16$ & $12 \pm 0.16$ & $11 \pm 0.24$ & --- & --- \\
\hline 6 & 4 & $14 \pm 0.08$ & $\mathbf{2 1} \pm 0.08$ & $14 \pm 0.08$ & $13 \pm 0.16$ & $12 \pm 0.16$ & $11 \pm 0.24$ & $6 \pm 0.24$ & $6 \pm 0.24$ \\
\hline 7 & 5 & $\mathbf{1 5} \pm 0.08$ & $11 \pm 0.24$ & $14 \pm 0.08$ & $13 \pm 0.16$ & $11 \pm 0.24$ & $\mathbf{1 3} \pm 0.16$ & $6 \pm 0.24$ & $6 \pm 0.24$ \\
\hline
\end{tabular}

PA2 concentration, ranging from $0.5,1,2,3,4$ and $5 \mu \mathrm{g} / \mathrm{ml}$ per disc. The PA2 was found to be significantly effective at $S$. aureus since the higher zone of inhibition $(21 \mathrm{~mm})$ was observed at 4 $\mu \mathrm{g} / \mathrm{ml}$ concentration compared to zone $(15 \mathrm{~mm})$ at $5 \mu \mathrm{g} / \mathrm{ml}$ inPA1. PA1 inhibited slightly more $(14 \mathrm{~mm})$ at $4 \mu \mathrm{g} / \mathrm{ml}$, compared to PA2 $(13 \mathrm{~mm})$ at $3 \mu \mathrm{g} / \mathrm{ml}$ against $S$. typhi.

PA1 showed steady inhibition of $K$. pneumoniae from 0.5 to $4 \mu \mathrm{g} / \mathrm{ml}(12 \mathrm{~mm})$ concentration, which then lowered at higher concentrations. PA2 showed inhibition at the highest concentrations $(13 \mathrm{~mm})$. The same trend was observed for both types of fractions when tested against $P$. aeruginosa, where only higher concentration showed slight inhibition. The results are summarized in Table 2. The antibacterial potential of the extract of $P$. foetida L. was too largely due to polyacetylenic compounds (Nicolls, 1970; Nicolls et al., 1973; Birner and Nicolls, 1973; Patil, 2010).

\section{CONCLUSION}

The proposed extraction procedure and compiled TLC data illustrate that quick and efficient extraction of bioactive fractions from $P$. foetida L. fractions characterization, followed by reliable UV analysis. The experiments can be performed on the large pool of samples to generate unique spectroscopic determination; which provides general overview on patterns of polyacetylene and their trends. The generated data could offer solid support for different applications, such as the use of these fractions in drug discovery, production and optimization of secondary metabolites, bioautography screening, and direct use in the pharmaceutical industry.

Present study concludes the importance of conventional knowledge of medicinal plants and their uses in common practices. The UV and TLC data could be proven as a prominent tool in validation and documentation of the customary treasure of herbal remedies. Moreover, the described solvent extraction procedure in this work can be used as a standard that is applicable to alike polyacetylenic compounds in related or other plant genera.

\section{ACKNOWLEDGMENT}

We express our sincere thanks to Department of Science and Technology (DST), Govt. of India for providing financial assistance under FAST TRACK scheme to corresponding author. Also we are thankful to Dr. P.V. Thakare, Reader, Department of Biotechnology, Sant Gadge Baba, Amravati University, Amravati for providing Oxacilin resistant bacterial cultures.

\section{REFERENCES}

Abascal K., Yarnell E. Nervine Herbs for Treating Anxiety. Altern. Complemen. Therap. 2004; 10: 309-315.

Afolayan A.J. Meyer J.J.M. The antimicrobial activity of 3, 5, 7- trihydroxy flavones isolated from the shoots of Helichrysum aureonitens. J. Ethnopharmacol. 1997; 57: 177-181.

Ahmed L., Mohammed Z., Mohammed F. Screening of some Indian medicinal plants for their antimicrobial properties. J Ethnopharmacol. 1998; 62:183-193.

Akhondzadeh S., Naghavi H.R., Shayeganpour A., Rashidi A., Khan M. Passionflower in the treatment of generalized anxiety: a pilot double-blind randomized controlled trial with oxazepam. J. Clin. Pharm. Therap. 2001; 26:363-367.

Allen E. H., Thomas C. A. An antifungal polyacetylene from diseased safflower (Carthumus tinctorius). Phytochem. 1971; 10:15791582.

Ambasta S. P. The useful plants of India, Publication and Information Directorate, CSIR, New Delhi, India, 1986; 433-437.

Banso A., Ngbde J.E.. Phytochemical screening and invitro antifungal properties of Fagara zanthoxyloides. JFA and E, 2006 ; (3 and 4) $: 8-9$.

Birner J., Nicolls J.M. Passicol an antibacterial and antifungal agent produced by Passiflora plant species: preparation and physicochemical characteristics. Antimicrob. Agent Chemother. 1973; 3: 105-109.

Blumenthal (ed.), Klein. 1997. Trans. German commission E therapeutic Monographs on Medicinal Herbs for human Use. American Botanical Council America.

Bohlmann F. (1971) In V.H. Heywood (Ed) Biology and Chemistry of the Umbelliferae. (pp.259-310).Academic Press, London.

Bradley P.R. British Herbal Compendium, Vol I. Bournemouth. British Herbal Medicine Association. 1992.

Chopra R. L., Nayar S.L. Chopra I.C. Glossary of Indian Medicinal Plants, Council of Scientific and Industrial Research, New Delhi, India. 1956; 186-187.

Chopra R.N., Badhwar R.L, Ghosh S. Poisonous Plants of India. Public Service Commission, Govt. of West Bengal, Calcutta, India. 1944; 469-472.

Cronquist A. An Integrated System of Classification of Flowering Plants. Columbia University Press, New York. 1981.

Dhawan K., Kumar S., Sharma A. Anti-anxiety studies on extracts of Passiflora incarnata Linnaeus. J. Ethnopharmacol. 2001a; 78: $165-170$.

Dhawan K., Kumar S., Sharma A. Anxiolytic activity of aerial and underground parts of Passiflora incarnata. Fitoterapia. 2001b; 72: 922-926. 
Dhawan K., Dhawan S., Sharma A. Passiflora: a review update. J. Ethnopharmacol. 2004; 94: 1-23.

Dhawan K., Kumar S, Sharma, A. Antiasthmatic activity of the methanol extract of leaves of Passiflora incarnata Linn. in mice. Phytother. Res. 2003; 17 (4): 401-403.

Echeverri F., Arango V., Quinones W., Torres F., Escobar G., Rosero Y., Archbold R., Passifloricins, polyketides alpha-pyrones from Passiflora foetida resin. Phytochemistry. 2001; 56: 881-885.

Esimone C.O., Adikwu M. U., Okonta J.M. Preliminary antimicrobial screening of the ethanolic extract from Lichen usnea subjloriddans (L). J. Pharm. Res. Dev. 1998; 3(2): 99-101.

European Committee for Antimicrobial Susceptibility Testing (EUCAST). Determination of minimal inhibitory concentration (MICS) of antibacterial agents by agar dilution. Clin. Micro. Inf. 2000; 6 (9): 509515

Fouqué A. Especes Fruitieres d'Amerique tropicale II fruits 1972; 27:120-139.

Harborne J.B. Photochemical Methods: A Guide to Modern Techniques of Plant Analysis. Chapman A. \& Hall. London. 1973; 279.

Hostettmann K., Marston A. (1990) In Studies in Natural Products Chemistry, Vol. 7, Atta-ur- Rahman, (Ed.). pp. 405-437. Elsevier, Amsterdam.

Ikegami F., Fujii Y., Ishihara K., Satoh T. Toxicological aspects of Kampo medicines in Clinical Use. Chem. Biol. Interac. 2003; 145: 23550 .

Izzo A.A. Drug interactions with St. John's Wort (Hypericum perforatum): a review of the clinical evidence. Planta Med. 2004; 54: 488491.

Jamode VS., Ganar N. Makode B. and Mahajan S.. Textbook of organic chemistry. 2nd ed. Bokey Prakashan, Amravati. (1998) 32.

Jones, W. P., \& Kinghorn, A.D. (2006) Extraction of Plant Secondary Metabolites. In S.D Sarker., Z. Latif \& A.I Gray (Ed.) Natural products isolation. 2nd ed. ( pp 321-351) Humana Press, Totowa, New Jersey.

Killip E. P. The American species of Passifloraceae. Publ. Field Mus. Nat. Hist. 1938; 19:1-613

Leung A.Y., Foster S. Encyclopedia of common Natural Ingredients used in food, drug and cosmetics. 2nd ed. John Wiley and Sons. Inc. (1996) New York.

Newall C.A., Anderson L.A., Pgillipson J.D. Herbal Medicine: A guide for health care professionals. The Pharmaceuticals press. London; 1996; 206-207.

Ngbede J., Yakubu R. A., Nyam D.A. Phytochemical screening for active compounds in Canarium schweinfurthii (Atile) leaves from Jos North, plateau state, Nigeria, Research Journal of Biological Sciences. 2008; 3(9): 1076-1078.
Nhut D.T, Khiet $\quad$ B. L. T., Thi N. N., Thuy $\quad$ D. T. T., Duy N., Hai N. T., Huyen P. X. (2007) High frequency shoot formation of yellow passion fruit (Passiflora edulis F. flavicarpa) via thin Cell Layer (TCL) Technology. In S. Mohan Jain and H. Häggman(Ed.) Protocols for Micropropagation of Woody Trees and Fruits. Springer Netherlands.

Nicolls J.M. Antifungal activity in Passiflora species. Ann. Bot. (London). 1970; 34: 229-337.

Nicolls J.M., Birner J., Forsell P. Passicol an antibacterial and antifungal agent produced by Passiflora plant species: qualitative and quantitative range of activity. Antimicrob. Agents Chemother. 1973; 3: 110- 117.

Obdeyi A., sofowora E.A. Phytochemical screening of Nigeria medicinal plants. Part II Liyodia. 1978; 403:234-246.

Patil, A.S., 2010. Exploring Passiflora incarnata L.: A medicinal plants secondary metabolites as antibacterial agent. Journal of Medicinal Plants Research Vol. 4(14), pp. 1496-1501.

Sofowora A. Medicinal plants and traditional medicine in Africa. John Wiley and Sons Ltd. Chichester. England (1982)142-146.

Sorensen N.A. The taxonomic significance of acetylenic compounds. Recnt. Adv. Phytochem. 1968; 1: 187-228.

Speroni E., Minghetti A. Neuropharmacological activity of extracts from Passiflora incarnata. Planta Med. 1988; 54: 488-491.

Swarbrick JT. The Australian weed control handbook.5th ed. Plant Press, Toowoomba Qld. (1981)342.

Waage J.K., Smiley J.T., Gilbert L.E. The Passiflora problem in Hawai'i; prospects and problems of controlling the forest weed $P$. mollissima (Passifloraceae) with Heliconiine butterflies. Entomophaga.1981; 26:275-284.

Wall M. E., Wani M. C., Brown D. M. effect of tannins on screening of plant extracts for enzyme inhibitory activity and techniques for their removal. Phytomedicine. 1996; 3:281-285.

Werner F., Okemo P., Ansorg R. Antibacterial activity of East African Medicinal plants. J. Ethnopharmacol. 1999; 60: 79-84.

Williamson EM. Okpako DG. and Evan F.J. Pharmacological methods in phytotherapy research vol.1. John Wiley and Sons Ltd. Chichester. England, (1996) 9-13.

Wolfman C., Viola H., Paladini A., Dajas F., Medina J.H.. Possible anxiolytic effects of chrysin, a central benzodiazepine receptor ligand isolated from Passiflora caerulea. Pharmacol. Biochem. Behav. 1994; 47: 1- 4

\section{How to cite this article:}

Patil A.S. and Paikrao H.M. Bioassay Guided Phytometabolites Extraction for Screening of Potent Antimicrobials in Passiflora foetida L. J App Pharm Sci. 2012; 2(9): 137-142. 